\title{
CANNABIS PERSONALIZATION: \\ CURATING PERSONALIZED CANNABIS EXPERIENCES THROUGH MACHINE LEARNING
}

\author{
by
}

\section{Julia Ho}

Bachelor of Journalism, Ryerson University, 2017

\author{
A Major Research Project \\ presented to Ryerson University \\ in partial fulfillment of the \\ requirement for the degree of \\ Master of Digital Media \\ in the program of Digital Media
}

Toronto, Ontario, Canada, 2019

(C) Julia Ho, 2019 


\section{Author's Declaration}

I hereby declare that I am the sole author of this MRP. This is a true copy of the MRP, including any required final revisions.

I authorize Ryerson University to lend this MRP to other institutions or individuals for the purpose of scholarly research.

I further authorize Ryerson University to reproduce this MRP by photocopying or by other means, in total or in part, at the request of other institutions or individuals for the purpose of scholarly research.

I understand that my MRP may be made electronically available to the public. 


\author{
Abstract \\ CANNABIS PERSONALIZATION: \\ CURATING PERSONALIZED CANNABIS EXPERIENCES THROUGH MACHINE \\ LEARNING \\ Julia Ho \\ Master of Digital Media \\ Digital Media \\ Ryerson University, 2019
}

With the recent legalization of cannabis in Canada on October 17, 2018, the opportunity for emerging tech to complement and improve the cannabis experience is vast. The legalization of an industry that has been operating in the dark for decades means ample newfound opportunity for government and corporate-funded collaboration, development and research. A specific area of opportunity for growth within the cannabis sector is through personalization.

Personalization is often performed via artificial intelligence — specifically machine learning - to develop a customized experience for users on various platforms. This is usually with the intention of targeted marketing. And while mass data collection serves the user by streamlining content to their assumed preferences, which then often directs them to businesses and products, product-tailoring still has vast potential for growth. Though a medical document for cannabis from a health practitioner may include broadband components to look out for, like "THC" and "CBD", or even suggest ratios of those cannabinoids there is typically no specification on strain type and best consumption methods.

Because the effects that cannabis has on a user varies from individual to individual and is dependent on not only their biometrics, but the various other terpenes and cannabinoids that exist in each strain beyond THC and CBD, cannabis users are missing out on opportunities to make the most of their use. Especially for those interested in cannabis to relieve specific symptoms, testing the vast amount of strains that exist and being able to identify the ideal product would be an arduous task on one's own.

Jibed is an app that would use the aggregation of user data to prescribe the most suitable strain of cannabis for that individual based on their specific conditions and body metrics. As the majority of the target audience (cannabis users in Canada) are already logged on to a multitude of data collecting apps (music, health, social, etc.), there is no shortage of data. The app would consider all the implications of the data, from one's health to mood deduced from the music they're listening to-just to name some-in order to achieve optimal prescriptions. 


\section{Acknowledgements}

I would like to extend my sincerest gratitude to Bradley Poulos, my supervisor and mentor throughout my MRP process. His patience and industry expertise motivated me to achieve higher with each step and his flexibility in guidance allowed me to make this project my own. I would also like to thank Dr. Anatoliy Gruzd, for his feedback and support as I began my MRP journey, and for seeing out the final days of my paper.

Of course, I thank my loving parents - Carly Wong and Anthony Ho-for their continued support in every aspect of my life and for raising me to be the determined young individual that I hope they are proud of. Their hard work my entire life has made it possible for me to not only be the first generation in my family to attend university, but to obtain a master's as well. Finally, I thank my partner, Julian Riley, for his utmost understanding and love. His unwavering support has given me the endurance to achieve what I have so far. 
Table of Contents

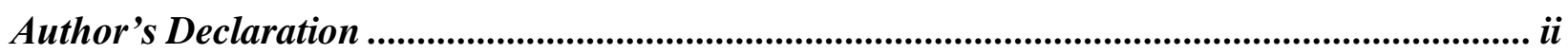

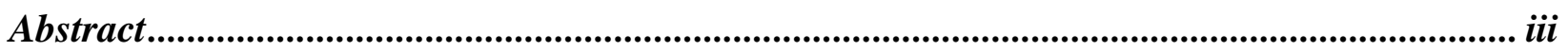

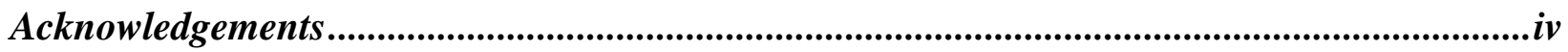

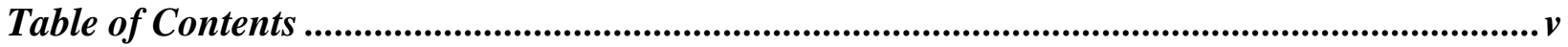

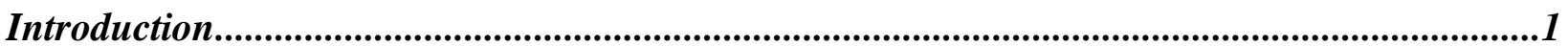

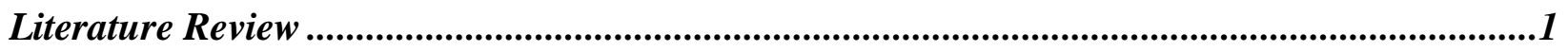

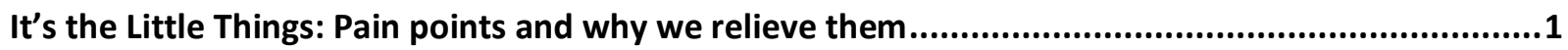

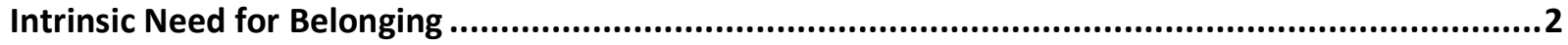

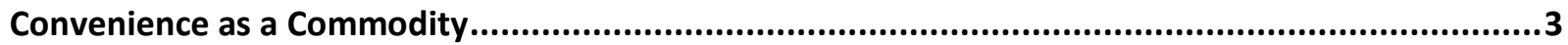

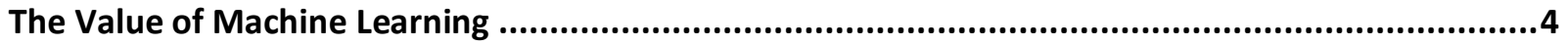

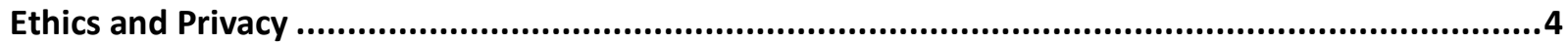

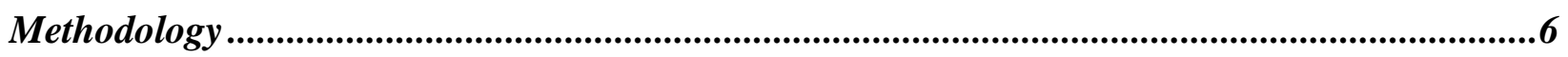

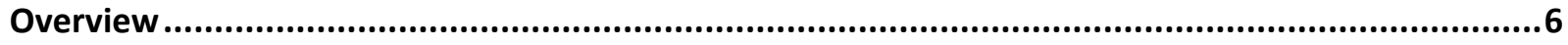

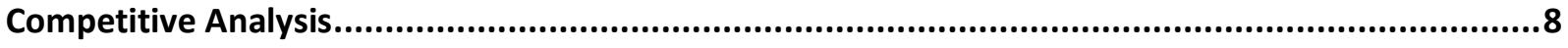

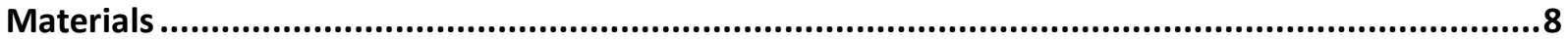

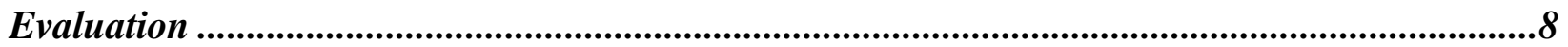

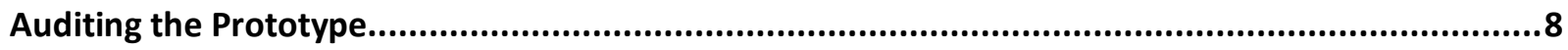

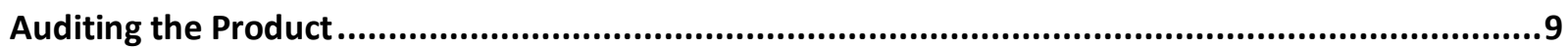

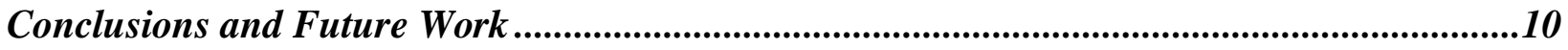

References

\section{List of Figures}

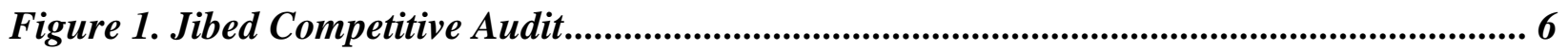

Figure 2. Jibed User Journey Map .................................................................................... 7

Figure 3. Jibed User Personas ........................................................................................................ 7

Figure 4. Jibed prototype home screen .................................................................................... 9

Figure 5. Data flow diagram .................................................................................................... 10 


\section{Introduction}

Within mere months of legalization, the Canadian cannabis industry already proved itself to be lucrative. In the first quarter of 2019 alone, there were 1.8 million daily cannabis users in Canada (Statistics Canada, 2019). That does not include weekly, monthly and occasional users. In the same time period, legal cannabis has been catching on, with 2.5 million (47\%) Canadian cannabis users obtaining cannabis from legal sources. Of those users, 646,000 were first-time users, doubling the estimation from 2018. All this is to suggest that cannabis use in Canada is increasing. Especially for young people who have grown up with digital platform integration, there lies a unique opportunity to connect cannabis users with an improved cannabis experience through personalization technology. According to studies, millennials desire access to personalization and are more likely to share personal data for a service (Aima, 2011). As it happens, cannabis use is also more common among millennials than any other age demographic (Deloitte, 2016, p. 4). With the vast amount of strain data that exists and our existing dependency on algorithmic sifting to auto-filter results, machine learning is an optimized pathway to the best possible cannabis experience. What is exciting is that cannabis use, though more popular among young people, is not exclusive to that demographic. In fact, half of the new users mentioned above were aged 45 or older and there has been a return from former cannabis users that are trying cannabis again post-legalization.

It is no secret that artificial intelligence is becoming ubiquitous with almost every aspect of our lives. Heavily intrigued by machine learning algorithms, I began to develop Jibed, an app that would aggregate data from the existing apps on your phone to select the best strains of cannabis to fit user profiles in 2016. I was inspired by a The Guardian (Mahdawi, 2016) article that explained how Spotify was able to determine their users' moods based on their music listening history. This paper explores the processes and research behind prototyping the beta version of the app, which encourages users to journal their cannabis experiences through an input form system. This function will not only give them feedback from their documented use to make informed decisions, but allow Jibed to build a database of personal metrics and how they interact with specific strains. With the mass amount of data that machine learning requires, this first iteration is crucial in producing the knowledge needed to feed the AI algorithm in the future.

\section{Literature Review}

\section{It's the Little Things: Pain points and why we relieve them}

Some of the most successful technologies are not necessarily those that rectify important and complex problems. Though there is no doubt that the critical issues of the world are deserving of solutions, the technology our societies possess grant us the privilege to access what many may consider small or insignificant problems. But problems, however small, are still problems and a nuisance to various degrees. At the top of Maslow's hierarchy of needs is the identifier for a life lived at full potential - one where we can augment all aspects of our lives to our best ability, Jibed aims to relieve humanity's "first-world," but very relatable pain point.

The dissonance in the cannabis industry lies in the fact that it possesses layers of elitist inaccessibility, contributing to consumers' feelings of isolation and lack of belonging. The popularity of digital and mobile platforms allows us to overcome many of the existing barriers to entry. Jibed capitalizes on a person's desire to understand their cannabis use and cannabis in 
general, in an otherwise complex and overwhelming field. Through discussing the human nature of belonging, we can begin to understand how Jibed will fuel its existence by being the steppingstone between the cannabis and its user.

\section{Intrinsic Need for Belonging}

Corporations understand the science of "public familiarity" and how that is "positively associated with people's expectations that others would be there for them" (Blokland and Nast, 2014, p. 1155). Public familiarity is described by Blokland and Nast as "the recognizing and being recognized in local spaces." This, they argue, "creates a comfort zone that allows people to feel they belong" (2014, p. 1155). Big tech has boomed into a multi-billion-dollar industry by creating solutions that we employ to satisfy our intrinsic need for connectivity. A social media platform like Facebook alone is worth over \$507 billion as of August 2019 (Macrotrends, 2019). This does not account for its subsidiaries or any businesses profiting through Facebook. The zone of comfort that our social media spaces provide are invaluable to us because of that inborn need for relationships with other people, thus allowing us to justify the endless amounts of capital we invest into them. This capital can be the ad revenue we generate, the time we spend, or the consent we give to our data collection.

As the cannabis space currently exists, experiences involving any and all steps related to cannabis consumption can be ostracizing for the uninformed user, breeding an opportunity for education. This kind of familiarity in this setting can be achieved through consuming knowledge and experiences; Jibed makes consuming cannabis information easy and attainable. Feeling a sense of familiarity is a crucial component for humans to feel like they belong and "people simply prefer to invest in the familiar" (Huberman, 2001, p. 659). For one to feel like they belong in a group, especially one that is niche, simple things like terminology and etiquette that is specific to that space can help immensely. Belonging is "having a reasonable understanding of the social codes and unwritten rules of the public space," (Blokland and Nast, 2014, p. 1144). Humans desire acceptance and being informed is a crucial step in feeling accepted in a community. Jibed helps educate users on cannabis products and information.

Humans are creatures of habit who covet familiarity, a trait that we project onto our work, routine living, as well as where and how we satisfy our basic need for human relationships. Many of our daily lives include habitual actions, whether in the form of intentional routine or simply gratifying actions (Engelbrecht, 2016, p. 34). Especially with the rise of modern technology and social media, our habits are more understood than ever.

The need for familiarity and belonging has been an innate characteristic since humans existed. From early nomadic tribes to the first forms of civilization during the Neolithic Revolution in Mesopotamia, how human have lived together has changed, but the one consistency is that we have stayed connected.

This century's tool for connection is easily quantifiable as the Internet and modern-day social media. As the cannabis space is relatively new and daunting, with information often consisting of heavy scientific jargon, it is not difficult to see how the average cannabis user may feel overwhelmed and isolated. A lack of understanding can create barriers to product consumption, ultimately reinforcing a negative cycle as a consumer becomes increasingly disenfranchised and discouraged. Kopp (2012, p. 191) argues, "Product literacy is a key ability in a consumption-driven society, composed of a fundamental set of skills and knowledge, needed to make 'satisfying' individual purchase choices but also to influence general health, economy and 
societal well-being." Especially because cannabis use has medical ties, Kopp makes a statement on how health care "information that is directed to patients often comes in print form and the desirable outcome is the patient's adherence to a prescription drug regimen" (2012, p.191). Yet cannabis prescriptions are often vague and lack specificity in terms of strain type and consumption method. Additionally, some users may choose to use cannabis to alleviate health symptoms but without direct medical recommendation and no point of reference when it comes to identifying a product that will work best for their case.

The cannabis experience, which often includes visiting dispensaries and interacting with the cannabis community, can be compared to other habitual aspects of our lives. For instance, we frequent our local café because we are familiar with the baristas or consistently dine at our favourite restaurants because we are comfortable with the menu. Joseph B. Nelson explains habits as having three components: a cue, routine, and the reward (release of dopamine). The brain develops specific neuro-pathways from repeating those steps, which Nelson says support the unconscious repetition of these habitual patterns (2014, p. 44-45). According to this theory, we crave the experiences that provide us that release of the feel-good hormone, which we associate with the products or methods that we use during said experiences. However, there exists a problem with how cannabis information is currently processed. It is not only inaccessible, but there is a lack of methods that allow users to track the effects of the plethora of different strains that exist in order to optimize their experience. The cannabis industry itself is riddled with barriers to entry, including heavy jargon and complex information. This strange exterior to a very profitable niche is inhibiting as it creates a severe sense of unfamiliarity for the typical user. Jibed mitigates these barriers by fuelling cannabis literacy, allowing for increased social accessibility to cannabis products, directly targeting our physiological need for belonging based on Maslow's hierarchy. As a secondary benefit, increased user aptitude encourages consumption and fosters business growth within communities.

\section{Convenience as a Commodity}

People will go to extraordinary lengths for convenience. Surely, it is why first-class flights and other luxuries exist. We order food boxes to our front doors instead of going to the grocery store, we pay extra to cab instead of taking public transportation-all in the name of convenience and ease. Convenience, although often a first-world concept, is the purveyor of vast industries and businesses. It permeates almost every aspect of our lives and it is no surprise that it increases exponentially with wealth. We invest in expensive memory foam mattresses and heated floors in the bathrooms. The one per cent goes as far as personal jets and mansions with elevators. Jibed provides a level of convenience much like how Uber, the modern alternative to taxis, does. It expedites what can be a frustrating process and relieves the stress of uncertainty. How Uber generates confidence by allowing its users to track their drivers and trips all at the touch of an app, Jibed does the same by instilling its users with informative product recommendations and use analyses. This is all to say that selling convenience is profitable and the customer segment is willing to spend-whether it is with money or other things with perceived value, such as personal data. The great thing about alternative methods of trade is that it is far less discriminatory than accepting only money as a form of payment. A free app allows users of all economic levels to participate by contributing, instead, their information and data, something that is arguably more valuable to Jibed in the long run. Beyond personal data 
however, users also indiscriminately pay with their time, which translates into advertising potential.

\section{The Value of Machine Learning}

Personal information is valuable as technology advances and promotes new uses of the mass amounts of data that has been collected. The economic shift towards personalization has been extreme and passive income has become the basic model for profit. Jibed is a crowdsourced app that extracts data from users and learn from users, calculating complex data and biometrics to recommend the most suitable strain for a particular individual. Crowdsourcing expedites the process of building a database as it allows for mass population of data as opposed to manual collection. Think of any successful digital platform today and they are most likely making use of a sophisticated data collection algorithm to curate content to our tastes. Instagram and other forms of social platforms alike knows what we want to see and it's eerily accurate, but it works. We voluntarily allow access to our information, while simultaneously contributing to use trends through our mere interactions with the app, and in return, we get personalized content that keeps us coming back. Similarly, machine learning technology would be implemented into Jibed. As individuals input their metrics, submit their interactions with different strains, and sync their data from other apps, the algorithm begins to translate that into conclusions. It sees which strains interact best with your metrics and is able to compare that to other users with similar metrics and what works for them. This allows for a more nuanced visual of your overall cannabis user profile.

Using machine learning, Jibed can accurately pinpoint profiles through "hop searches", which is a method of collecting data from a pinpointed target, and then everyone they communicate with, and everyone that person communicates with and so on and so forth will have their data collected, too (Schneier, 2016, p. 31-33). For example, one may have been having particularly good experiences when consuming a specific strain of cannabis this month, and the app knows this because of their journal inputs. When trying to recommend products with similar results, this same app might have previously made suggestions based on matching keywords and tags. With machine learning algorithms, suggestions become increasingly nuanced and accurate beyond mere keywords. Based on similar metrics, machine learning can make user inferences of user preferences for a network of people, even across many degrees of separation, which only gets more sophisticated as the algorithm is fed more information.

\section{Ethics and Privacy}

The exploitation of an intrinsic human characteristic, though seemingly harmful, is still ethically ambiguous in a context where we support and thrive under capitalism. Though leveraging the behavioural attitudes of people who use digital platforms, such as the addictive tendencies many of us have with our devices and software, may seem immoral, it is important to consider these threads and how they function within the broader context of society. For example, one may argue that Jibed takes advantage of one's need for belonging for capital gain, all the while capturing their personal data. Some may even go so far as suggesting the convenience an app like Jibed provides creates a sort of dependence and reliance on the service, reinforcing a larger structural impact Jibed may have on a society. Some of these impacts may include the eradication of smaller local organizations or businesses that simply cannot compete with Jibed. 
However, it is not without benefit that users voluntarily interact with these digital platforms and society often benefits as a whole as well. New methods are adopted because they provide the user with something that works to satisfy what they are looking for. But people are taking precautions because they are uncomfortable with how data is being collected. A recent survey showed that 50 per cent of online Canadians opted to censor their social media posts in order to prevent companies using their data for advertising (Gruzd, Jacobson, Mai, Dubois, 2018, p. 11). Surely businesses have been preying on our human tendencies to achieve success since the dawn of business and industry. After all, the concept of marketing and selling inherently involves visceral persuasion, but what about the ethics of data collection through these everyday apps in websites?

Nevertheless, it is crucial to acknowledge the potential privacy and ethical implications that personalization may cause. This technology and our dependency on it directly correlate to the amount of personal data we give to the companies that in turn use that data to further sell to our behaviours through analysis. Especially to the degree that much of the population exhibits addictive behaviours with their devices, it is important to consider the ethics of contributing to and perpetuating our digital habits. Though not all habits are negative, the average Canadian will likely possess some habitual qualities that are at best slightly inhibiting, or at worst, completely detrimental to their lives. Habits, once formed, allow for a "mindless approach to life - at least in the area of the behaviour" and that "an unconscious, automatic behaviour makes it impossible to choose a different behaviour" (Nelson, 2014, p. 45).

It can appear as though some of us have relinquished some aspects of basic control over our impulses when it comes to these apps, raising the question of how much freedom we actually have from big tech and what that means for our lives politically and socially. The mere use of our data to tailor ads or personalize usage seems innocent enough, often even practical. It saves us hours from searching through infinite amounts of online data and rather suggests what we may be looking for. Yet with most technology, the unintended consequences can be far more malicious than anticipated, and a mass collection of data can and has begun to lead to more serious costs. The grey areas of legal interference with personal data are massive and its lines are extremely blurry. At what point do corporations become obligated to share data with the government, if ever, and what does that mean in terms of safety, privacy, and an ever-widening social class disparity? As data collection processes and practices mature and evolve, it would likely lead to exacerbation of existing socio-political problems, such as the disproportionate amount of poor and marginalized folks being incarcerated. Especially in the context of cannabis, to what extent might a company like Jibed be expected to report to the government when a user's data suggests that they might be above the legal possession limit, for example. Furthermore, what are the parameters in regard to government forces, domestic or foreign, that allow for the access and potential manipulation of data to target individuals, specifically the marginalized? A constant surveillance of those communities through their data can only support existing hegemonic structures. The kind of push for data collection that we are headed towards promotes an ecosystem that continuously punishes those who simply do not have access to the education to protect their privacy otherwise, nor the wealth to dispute the consequences.

Ultimately, it is clear to see that a number of ethical issues arise when dealing with a technology that involves exercising fundamental human behaviours that are natural and inborn. Through understanding how habits are formed and what role that plays in a business-consumer market, this paper has begun to unravel the nuances in this context. Furthermore, it was realized that unintended consequences are at the forefront of any innovation, and that in turn presents an 
entirely complex set of ethical issues. Jibed aims to tackle these concerns by creating a transparent data transaction model - being open to the user about what pieces of their information will be collected. When the app makes a suggestion for a product to the user, it will explain which parts of the individual's data informed the technology to help it make its conclusion. This is in hopes that it will help eliminate some anxieties around the uncertainty of how users' data is used. In addition, Jibed will address these key issues right at the forefront through user consent education and through techniques like differential privacy, which will be expanded upon in the "Conclusions and Future Work" section.

\section{Methodology}

\section{Overview}

This project encompasses a prototype produced from extensive secondary research, including sources listed in this paper. Upon reviewing available collateral, including statistical analyses and strain data on the cannabis industry and its market, I conducted a market analysis, a competitive audit (See Figure 1) and mapped out user journeys (See Figure 2) based on my user personas (See Figure 3).

\section{Variety \& Information}

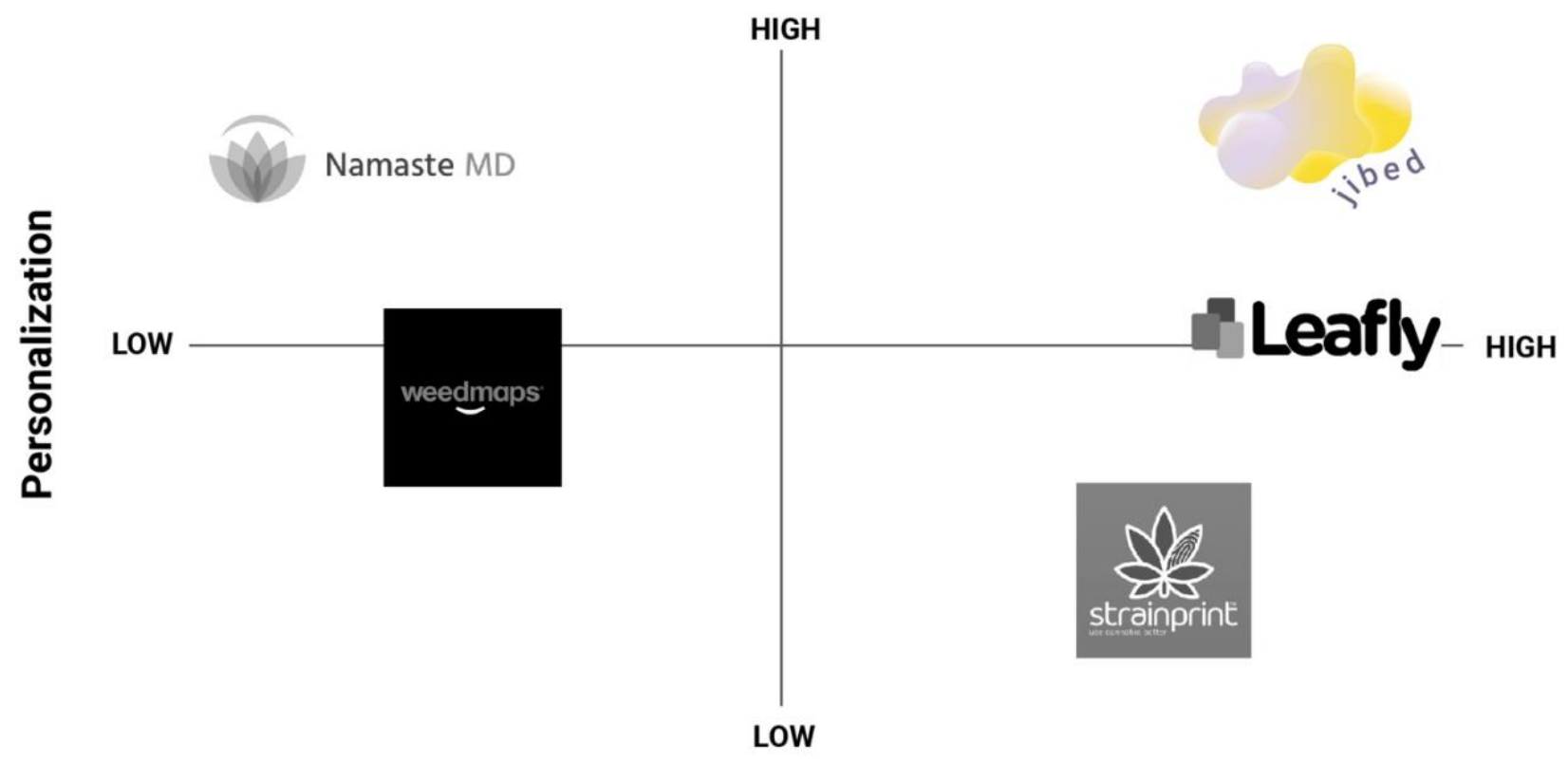

Figure 1. Jibed Competitive Audit. 


\section{Search}

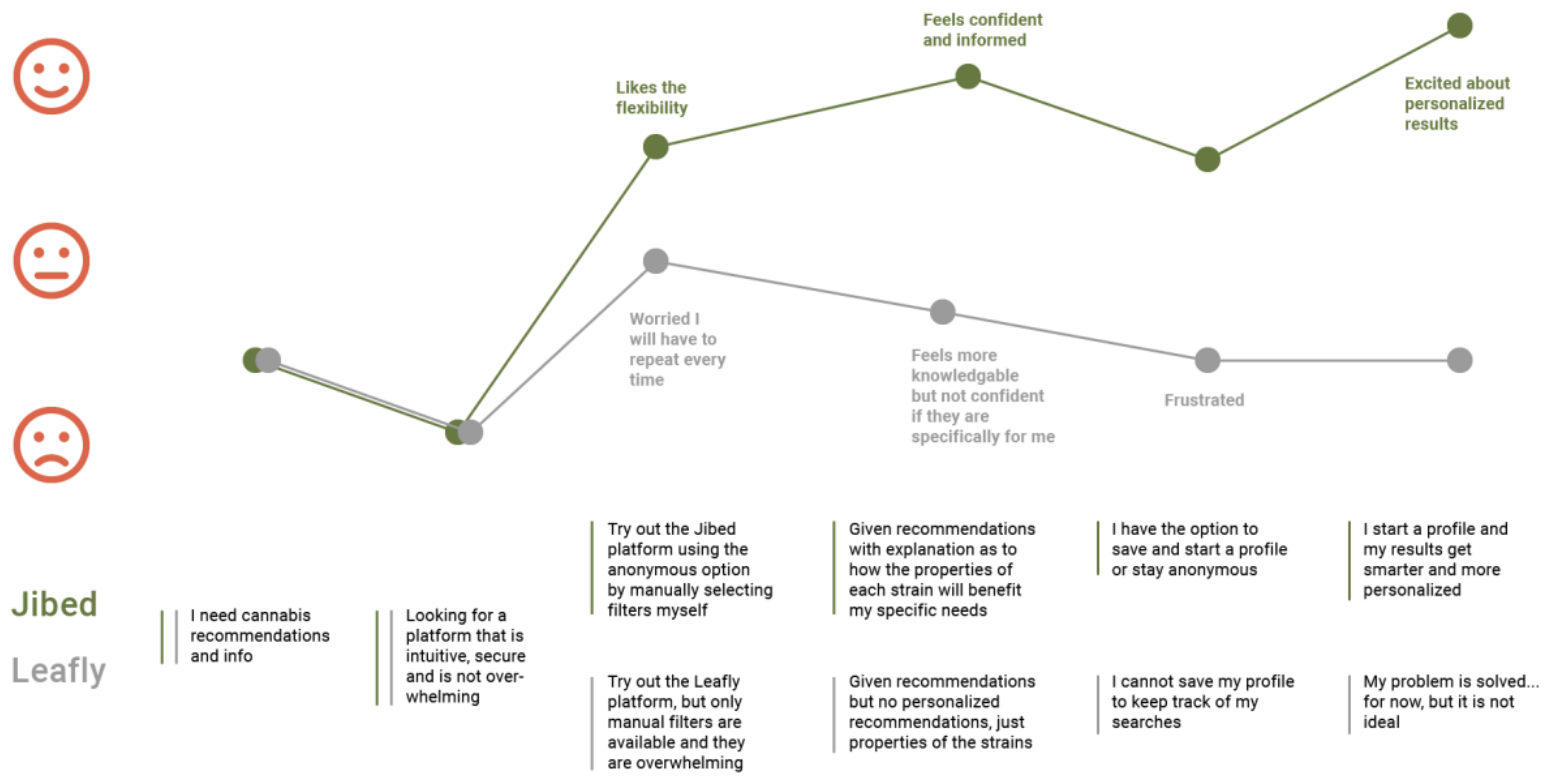

Figure 2. Jibed User Journey Map.

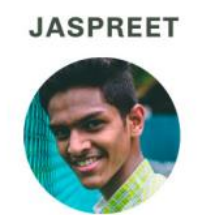

Occasional User

As a student who occasionally uses cannabis for back pain, I want to make the most out of my cannabis use by finding the most suitable strains.

\section{BEHAVIOURS \\ Knows the basics of cannabis Wants to find the best strains for his pain \\ PAIN POINTS \\ His prescriptions do not specify strains or product type Does not want to waste time testing}

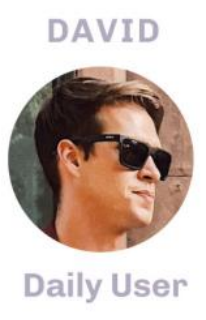

As a young professional with disposable income who is a daily cannabis user, I do not know much about strains and would like personalized recommendations.

\section{BEHAVIOURS}

Pays for concierge services Uses legal cannabis products Wants personalized experiences

\section{PAIN POINTS}

Too busy to research strains Feels overwhelmed by all the cannabis information

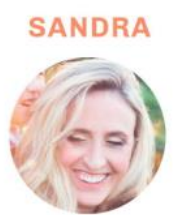

Returning Cannabis User

As a mom in her 50 s. I want to start using cannabis again, but don't know where to begin. I would like to learn more about cannabis.

\section{BEHAVIOURS}

Wants to use legal cannabis products

Wants to make informed decisions

\section{PAIN POINTS}

Feels overwhelmed and uninformed

Does not know what she likes

Figure 3. Jibed User Personas.

By conducting this journey map, I was able to visualize what needs the user will require at what stage, thus informing my experience design from an empathetic level. My personas were created based on a series of pain points I derived from my research. Using that as an opportunity to fulfill a market gap, I led my design with the user needs of my personas in mind. My prototyping methods takes a heavy user experience (UX) design approach, building low-fidelity wireframes 
with usability in mind first, before moving forward mid-fidelity iterations and finishing with a polished high-fidelity product. A wireframe (which is a low-fidelity initial design of a product, typically is done in greyscale) includes the foundational components of a product layout and its key functions. As the project moves through to high-fidelity stage, which is (or is close to) a polished prototype that includes full colour scheming and visual design elements, the in-between phase is often regarded as mid-fidelity; mid-fidelity begins to build on the wireframes, incorporating more detail and user interface (UI) components, such as graphics and colour. Prototyping for a mobile application product is essential as it provides a necessary platform to conduct usability testing in order to continue iterating as I build the product.

\section{Competitive Analysis}

A competitive analysis or audit is conducted by businesses, particularly young businesses, in order to identify its standing within its field and how it competitively compares to its adversaries. Jibed is positioned as being a strong competitor within its industry in terms of both personalization and information variety - the main objectives of the product. Though some apps perform similar functions, most only offer one or the other. Leafly would be Jibed's biggest competitor, as it not only has a large catalogue of products with very in-depth information, but the app also allows for some personalization. However, Leafly's personalization is done through manual filters, making Jibed the more convenient and expert solution as it works passively to make accurate and informed decisions about its users.

\section{Materials}

The wireframing and prototyping of Jibed was completed using mock-up programs Sketch and AdobeXD. Because of my use of multiple design programs, I used InVision to sync my project screens and produced a prototype version of Jibed. I used Adobe Illustrator to create some of my visual assets, while also supplementing those royalty free images from Unsplashed.com and royalty free graphic assets from TheNounProject.com.

\section{Evaluations}

\section{Auditing the Prototype}

When identifying user personas for Jibed, there were three major pain points that my project aimed to fix. Cannabis users find cannabis information complex and overwhelming, they don't know how to optimize their experience, and they find it difficult to find their best-suited strains. By enlisting a thoughtful UX design approach, I iterated frequently to design with user needs as a focus in order to find a solution that was accessible. The three user personas that were assessed include David, Jaspreet and Sandra (See Figure 3). 
The most recent iteration of the app (see Figure 4) accesses user needs through a multitude of functions, including an experience journal and product/content recommendation. As

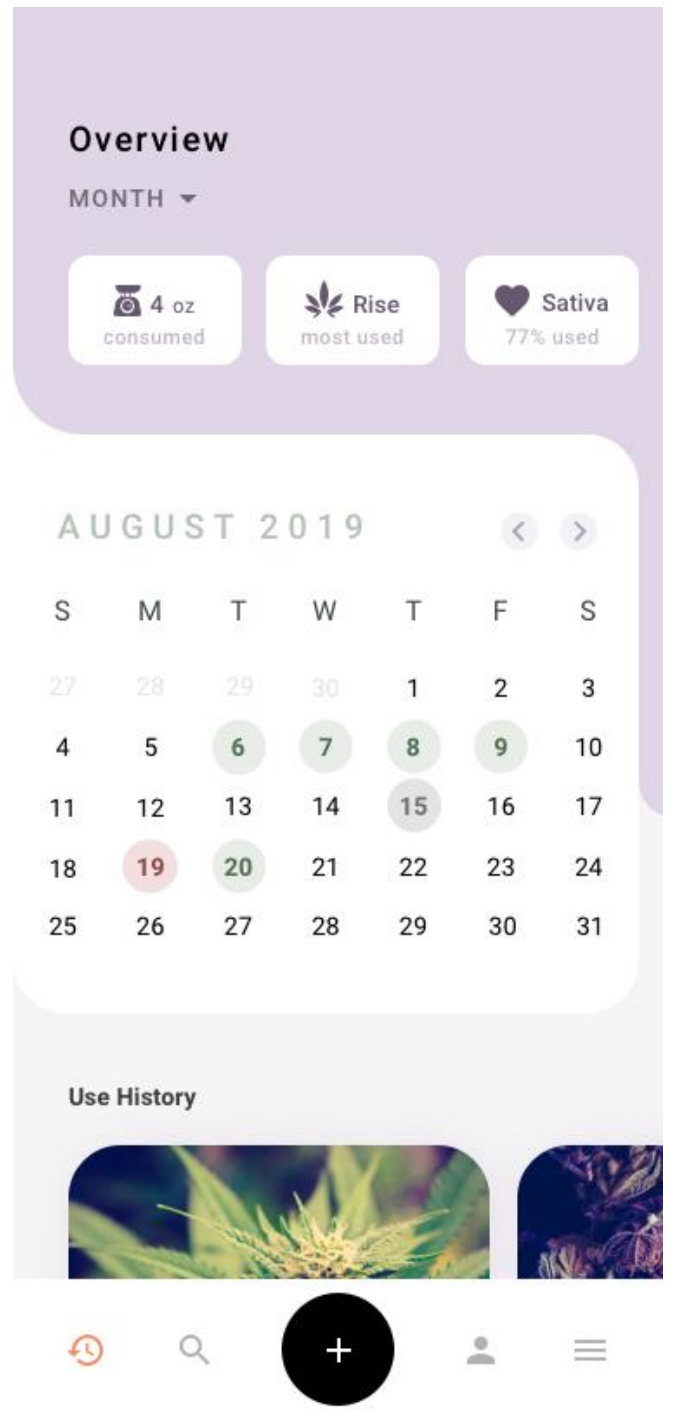

Figure 4. Jibed prototype home screen. https://bit.ly/30Iut 9 U for full prototype. these functions work to relieve their pain points, specifically the inability to track and optimize cannabis use and a lack of existing cannabis personalization, all functions simultaneously coexist to create an accessible and easily digestible presentation of typically complex information. This is extremely important as it refines all the difficult, but important details of cannabis use into something the average user can understand. The dashboard presents an overview of users' most used strain type and a history of their cannabis consumption . By creating a visual representation of their use over the course of a specified time period, users can compare their own experiences between themselves to make informed decisions. Meanwhile, the app compares their experiences with those of others to make enhanced suggestions. A key feature of the app is its ability to recommend strains based on personal use history, metrics, and data provided by the user on their experience. The "discover" tab provides suggestions for strains you might like by correlating individual user statistics with other users. Unlike opaque recommendation functions that are on the market, the suggestions provided by Jibed give users deep insights into what informed the recommendations. The model is transparent with user data compared to traditional data mining. The most crucial concept of this version is the user input form which allows for the tracking of experiences. The input form minimized the need for manual entries of personal data without sacrificing the ability to curate responses for nuanced experiences. By auto-populating sections, such as "body metrics", with data extracted from integrated apps, not only does it provide more accurate personal vitals but automates an otherwise tedious task of manually inputting one's own metrics. Other data inputs are given selections to mitigate excess typing and to streamline the options a user has.

\section{Auditing the Product}

The success of the training model is dependent on user interaction. The more input give the app access to their data, the more refined the algorithm gets at finding suitable matches for each individual. The human propensity for habitual fluency and dependency on our mobile devices to navigate and dictate our lives already creates a springboard for adoption of this product. During the initial launch period, it may be necessary to provide incentives to attract subscribers, such as providing users social credit for using existing platforms or giving users 
rewards with monetary value. This would be an ideal opportunity to create partnerships with businesses: they join our platform and provide non-user specific data on their products that can be fed into our algorithm to produce recommendations, meanwhile exposing our user segment to their products. If a user discovered a business collaborator through Jibed, the business can offer a discount or freebie to the user, which encourages users to join their business platform (consumer culture simply cannot resist free things). Even though Jibed does not provide monetary economic value, it provides value by way of providing personalization/ comfort and convenience - things that our culture often holds in higher regard than money. When things are free, they give us an emotional charge. Shampanier, Mazar and Ariely (2007, p. 749-750) conclude that when products are free, or "zero price", people tend to participate more because "free products invoke norms of social exchange, which can create higher value for the product in question." These incentives provided in partnership with cannabis businesses (e.g. an in-store discount when using Jibed to find a recommendation for the first time) would be free for Jibed, as they are providing the benefit of exposure to the business.

\section{Conclusions and Future Work}

While the beta version of Jibed encourages users to journal their personal experiences with individual strains of cannabis, this stage of development is particularly crucial for the ultimate implementation of a fully-functioning machine learning (ML) algorithm. ML requires immense amounts of data, which our platform will have collected through our users' inputs as more users subscribe to our app. In conjunction with APIs from aggregated apps, the future version of Jibed will provide users with recommendations that have been supported by not only their personal data but cross-referenced with users that share similar metrics. Because the app relies heavily on data, ML will be backbone technology of Jibed. ML algorithms will constantly update and refresh its understanding of the user's data, which then allows it to refine its profile on the specific user. Artificial Intelligence will be integrated more within the interface design, perhaps through a chatbot that acts as a guide as you navigate the app or ask it questions - a fantastic way for unsophisticated users to get acquainted. This is particularly useful for the busy user as it also acts as a filtering system to shortcut to what the user is specifically looking for.

In sum, the idea is to directly generate revenue from the consumer by providing a service that involves analysis of the consumer's data, which is then essentially given back to the user as a product that directly benefits them. Compared to the traditional iteration of data analysis that keeps its findings elusive to users, this new approach works to eradicate many of the ethical and privacy concerns revolving the sharing of intimate personal details. In the previous model of ad targeting, revenue is generated in layers by indiscriminately throwing ads at an individual that align with their profile in hopes that they are persuaded enough to act on their capitalist instincts. Jibed presents a fresh model that allows users to understand how and why their passive and nonpassive digital interactions influence the profile that is created for them in respect to personalization. A user's trust is extremely important and rightly so, as we are dealing with their personal data regarding precious topics, such as health and cannabis. Jibed's ML algorithm will hope to introduce differential privacy as a means to further combat privacy concerns. Differential privacy helps prevent the identification of individuals and their private data. It does this by introducing the dataset to noise that is specifically engineered and calculated to the sensitivity of the algorithm so that it does not interrupt its core function. By providing "a mathematical definition for the privacy loss that results to individuals when their private information is used to 
create AI products", it produces a "differentially private dataset that cannot be reverse engineered by an attacker" (Georgian Partners, 2019). Ultimately, by detailing the reasons why each recommendation is given to a user and which pieces of their data impacted that decision, as well as incorporating differential privacy technology, Jibed aims to move towards an era of transparency when it comes to data mining and personalization. 


\section{References}

Aima. (2011, May 10). How Generation Y will Reshape Customer Loyalty. Retrieved June 28, 2019 from Aima: https://corp.aimia.com/newsroom_trashed/news-releases/howgeneration-y-will-reshape-customer-loyalty

Blokland, T., \& Nast, J. (2014). From Public Familiarity to Comfort Zone: The Relevance of Absent Ties for Belonging in Berlin's Mixed Neighbourhoods. International Journal of Urban and Regional Research, 38(4), 1142-1159. doi:10.1111/14682427.12126

Deloitte. (2016). Recreational Marijuana - Insights and Opportunities, 1-12. Retrieved from https://www2.deloitte.com/content/dam/Deloitte/ca/Documents/Analytics/ca-enanalytics-DELOITTE Recreational Marijuana POV - ENGLISH FINAL_AODA.pdf

Engelbrecht, C. (2016). CREATURES OF HABIT THE CONSISTENT LEADER.Accountancy $S A$, , 34-35. Retrieved from http://ezproxy.lib.ryerson.ca/login?url=https://searchproquest-com.ezproxy.lib.ryerson.ca/docview/1774548701 ?accountid=13631

Georgian Partners. (2019, February 25). Epsilon: Differential Privacy for Machine Learning Using MXNet. Medium. Retrieved from https://medium.com/apache-mxnet/epsilondifferential-privacy-for-machine-learning-using-mxneta4270fe3865e\#targetText=Introducing Differential Privacy\&targetText=It works by injecting noise, data analysis or model performance.

Gruzd, A., Jacobson, J., Mai, P., \& Dubois, E. (2018). Social Media Privacy in Canada. SSRN Electronic Journal. doi: 10.2139/ssrn.3195503

Huberman, G. (2001). Familiarity Breeds Investment. The Review of Financial Studies, 14(3), 659-680. Retrieved from http://www.jstor.org/stable/2696769

Kopp, S. W. (2012). Defining and conceptualizing product literacy. Journal of Consumer Affairs, 46(2), 190-203. doi:10.1111/j.1745-6606.2012.01231.x

Macrotrends. (2019). Facebook Net Worth 2009-2019|FB. Retrieved August 28, 2019 from Macotrends: https://www.macrotrends.net/stocks/charts/FB/facebook/net-worth

Mahdawi, A. (2018, September 16). Spotify can tell if you're sad. Here's why that should scare you. Retrieved from https://www.theguardian.com/commentisfree/2018/sep/16/spotifycan-tell-if-youre-sad-h eres-why-that-should-scare-you

Schneier, B. (2016). Data and Goliath: The Hidden Battles to Collect Your Data and Control Your World. New York: W.W. Norton \& Company.

Shampanier, K., Mazar, N., \& Ariely, D. (2007). Zero as a Special Price: The True Value of Free 
Products. Marketing Science, 26(6), 742-757. Retrieved from

http://www.jstor.org/stable/40057223

Statistics Canada. (2019). National Cannabis Survey, first quarter 2019. Retrieved June 28, 2019 from Statistics Canada:

https://www150.statcan.gc.ca/n1/daily-quotidien/190502/dq190502a-eng.htm

Nelson, J. B. (2014). Habits: Who's in Charge? AADE in Practice, 2(6), 44-47.

doi:10.1177/2325160314552515 